\title{
Synthesis and Phase Behavior of New Amphiphilic PEG-Based Triblock Copolymers as Gelling Agents for Lamellar Liquid Crystalline Phases
}

\author{
Nelle L. Slack, ${ }^{\dagger}$ Mathias Schellhorn, ${ }^{\ddagger}, \S$ Petra Eiselt, ${ }^{\dagger}$ Michael A. Chibbaro, ${ }^{\dagger}$ \\ Uwe Schulze, ${ }^{\dagger}$ Heidi E. Warriner, ${ }^{\dagger}$ Patrick Davidson, ${ }^{, t}, l$ \\ Hans-Werner Schmidt, ${ }^{*, \pm}$ and C. R. Safinya*,t
}

Materials Department, Physics Department, and Biochemistry and Molecular Biology Program, University of California, Santa Barbara, California 93106, and Makromolekulare Chemie I and Bayreuther Institut für Makromolekülforschung (BIMF), Universität Bayreuth, 95440 Bayreuth, Germany

Received J une 8, 1998; Revised Manuscript Received September 14, 1998

\begin{abstract}
We report the first evidence of the potential of new amphiphilic ABA-triblock copolymers as gel ling agents for lamellar liquid crystalline $L_{\alpha}$ phases. Recently, we described a new type of Iamellar hydrogels which are not based on a polymer network swollen in water but are obtained by the addition of small amounts of a nonionic polymer surfactant to the fluid lamellar $L_{\alpha}$ phase of the dimyristoylphosphatidyl-chol ine(DMPC)/pentanol/water system. In contrast with these previously reported gelling agents which were all AB-diblock copolymers, the novel ABA-triblock copolymers consist of double chain hydrophobic moieties (A) attached to each end of a poly(ethylene glycol) chain (B). The synthesis of these new macromol ecules and their gelation properties are described. The comparison of these novel lamellar hydrogels with those based on the AB-diblock copolymers provides direct evidence for the existence of cross-bridging conformations of the ABA-triblock copolymers between adjacent membranes.
\end{abstract}

\section{Introduction}

Hydrogels of polymer networks constitute a very important class of "soft" matter materials from both scientific and technol ogical viewpoints. Their uses span diverse areas from the food industry to the medical and biotechnological industries in implants, tissue replacements, drug delivery systems, and bioseparations. ${ }^{1-6}$ Poly(ethylene glycol) (PEG) is a nonionic water soluble polymer which has been studied extensively in a broad range of scientifically and technologically important problems in colloi dal science and complex fluids. ${ }^{7}$ M ore recently, because of its extremely low immunogenicity, it has been used to prepare hydrogels for numerous biomedical applications.

We have recently developed a different class of hydrogels which are based on fluid membranes (Figure 1) comprised of the lipid DMPC (dimyristoyl-phosphatidyl-choline) and the cosurfactant pentanol with small amounts of an amphiphilic AB-diblock copolymer. ${ }^{8,9}$ These copolymers, also called PEG-surfactants, consists of a hydrophilic PEG chain covalently linked to a hydrophobic moiety. Such macromolecules are hydrophobically anchored but free to diffuse within the fluid membrane. There are striking differences between these membrane-based liquid crystalline biogels, labeled $\mathrm{L}_{\alpha, \mathrm{g}}$, and isotropic hydrogels of polymer networks. For example, as the amount of water is increased, less polymer is required for gelation. Furthermore, whereas even concentrated (>50 wt \%) free PEG - water mixtures do not gel, gelation occurs in lamellar mixtures contain-

* To whom correspondence should be addressed.

† University of California.

‡ Universität Bayreuth.

§ Permanent address: Boehringer Ingel heim KG, 55216 Ingelheim, Germany.

" Permanent address: Laboratoire de Physique des Solides (CNRS), Bat. 510, Université Paris Sud, 91405 Orsay, Cedex, France.

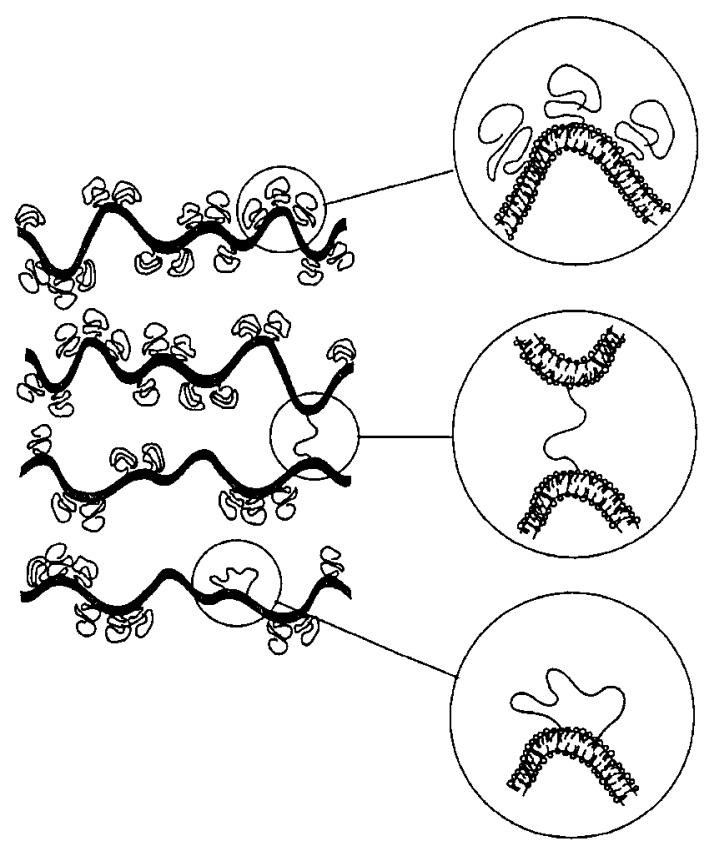

(a)

Figure 1. Schematic representation of undulating fluid membranes composed of a lipid (DMPC), a cosurfactant (pentanol) and amphiphilic block copolymers: (a) amphiphilic AB-diblock copolymers in mushroom configurations; (b) ABAtriblock copolymer in a bridging configuration; (c) ABA-triblock copolymer in a looping configuration.

ing as little as 0.5 wt \% of PEG-surfactant. The addition of the cosurfactant pentanol to membranes consisting of DMPC thins the bilayer membrane which leads to the decrease of its bending rigidity $k \approx \mathrm{k}_{\mathrm{B}} \mathrm{T}^{10}$ and allows us to explore the swollen Iamellar regime ${ }^{11}$ where the biogel is stable. The new physical gel phase has the same liquid-crystalline lamellar symmetry as that of the usual fluid $L_{\alpha}$ phase but displays threedimensional elastic properties. 
a) Amphiphilic AB-Diblock Copolymer<smiles>CCCCOc1ccc(C(=O)C(C)(C)OCCCOC)cc1OCC(C)(C)C</smiles>

b) Amphiphilic ABA-Triblock Copolymer

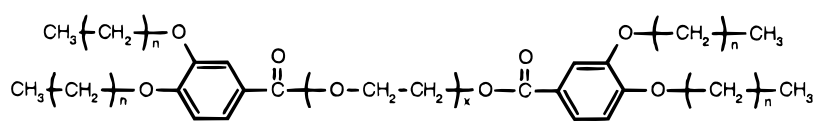

Figure 2. Chemical structures of amphiphilic AB-diblock copolymers $\mathbf{5 a}-\mathbf{c}$ and $\mathbf{6 a}-\mathbf{c}$ and of amphiphilic ABA-triblock copolymers 8a-e based on 3,4-(alkyloxy)benzoic acid and poly(ethylene glycol) segments.

In this paper, we describe the synthesis of a new series of ABA-triblock copolymers which consist of double chain hydrophobic 3,4-(alkoxy)benzoic acid moieties (A) attached on each end of a PEG chain (B) (Figure 2a). We also describe the synthesis of two series of AB-diblock copolymers consisting of a double chain hydrophobic 3,4-(alkoxy)benzoic acid moiety (A) attached only to one end of a PEG chain (B) which has not been published before (Figure $2 \mathrm{~b}$ ). We demonstrate for the first time the gelation properties of the ABAtriblock copolymers through visual inspection of test tubes, optical microscopy and small-angle X-ray scattering. In principle, these novel macromolecules can adopt not only looping conformations when both endanchors are in the same membrane but also original cross-bridging conformations with the end-anchors in opposing membranes (Figure 1). The detailed comparison of these new lamellar hydrogels with the previously reported ones based on the AB-diblock copolymers provides direct evidence for the cross-bridging conformations of the ABA-triblock copolymers.

\section{Experimental Section}

Materials. Protocatechuic acid ethyl ester (98+ \%) $(\mathrm{TCl})$, 1-bromotetradecane (98\%) and 1-bromooctadecane (96\%) (both Acros), thionyl chloride (97\%) (Aldrich), and all other conventional reagents were used as received. Poly(ethylene glycol)s of number-average molecular weights $\left(M_{n}\right)$ of $200\left(M_{w} / M_{n}=\right.$ $\left.1.05, D_{n}=4\right), 600\left(M_{w} / M_{n}=1.12, D_{n}=13\right), 2000\left(M_{w} / M_{n}=\right.$ $\left.1.04, D_{n}=45\right), 4600\left(M_{w} / M_{n}=1.06, D_{n}=104\right)$, and 8000 $\left(\mathrm{M}_{\mathrm{w}} / \mathrm{M}_{\mathrm{n}}=1.06, \mathrm{DP}_{\mathrm{n}}=181\right)$ and poly(ethylene glycol) mono methyl ethers of number-average molecular weights of 750 $\left(\mathrm{M}_{\mathrm{w}} / \mathrm{M}_{\mathrm{n}}=1.07, \mathrm{DP}_{\mathrm{n}}=16\right), 2000\left(\mathrm{M}_{\mathrm{w}} / \mathrm{M}_{\mathrm{n}}=1.11, \mathrm{DP}_{\mathrm{n}}=45\right)$, and $5000\left(M_{w} / M_{n}=1.10, D P_{n}=113\right)$ were purchased from Aldrich. The poly(ethylene glycol)s were dried at $110{ }^{\circ} \mathrm{C}$ for 2 $h$ in a vacuum prior to use. DMPC of a purity $>99 \%$ was purchased from Avanti Polar Lipids Inc., and pentanol of $>99 \%$ purity was purchased from Sigma Chemical Co.; both compounds were used as received. We also used purified $18 \mathrm{M} \Omega$ water provided from a Millipore unit.

Characterization. ${ }^{1 \mathrm{H}} \mathrm{NMR}$ measurements were carried out on a Gemini $200 \mathrm{MHz}$ spectrometer at $20{ }^{\circ} \mathrm{C}$ in $\mathrm{CDCl}_{3}$. FT-IR spectra were recorded with a Perkin-EImer FT-IR 1600 spectrometer. Thermal transitions were determined with a Perkin-EImer DSC 7. The heating and cooling rates were 10 $\mathrm{K} / \mathrm{min}$. Molecular weight determination was performed on a Waters GPC system equipped with a W510 pump (eluent, THF; flow rate, $0.5 \mathrm{~mL} / \mathrm{min}$ ), two PL columns (500 and 1000 $\AA$ pore size), a RI detector (W410) and an UV detector (W440, $254 \mathrm{~nm}$ ). The GPC was calibrated with polystyrene standards (PSS).

Synthesis of Monomers. The synthesis of 3,4-bis(tetradecyloxy) benzoic acid chloride (2b) and 3,4-bis(octadecyloxy) benzoic acid chloride (3b) was carried out in analogy to the procedure described by Malthête et al. ${ }^{12}$ and Lattermann et al. ${ }^{13,14}$ The reaction sequence is outlined in Figure 3.
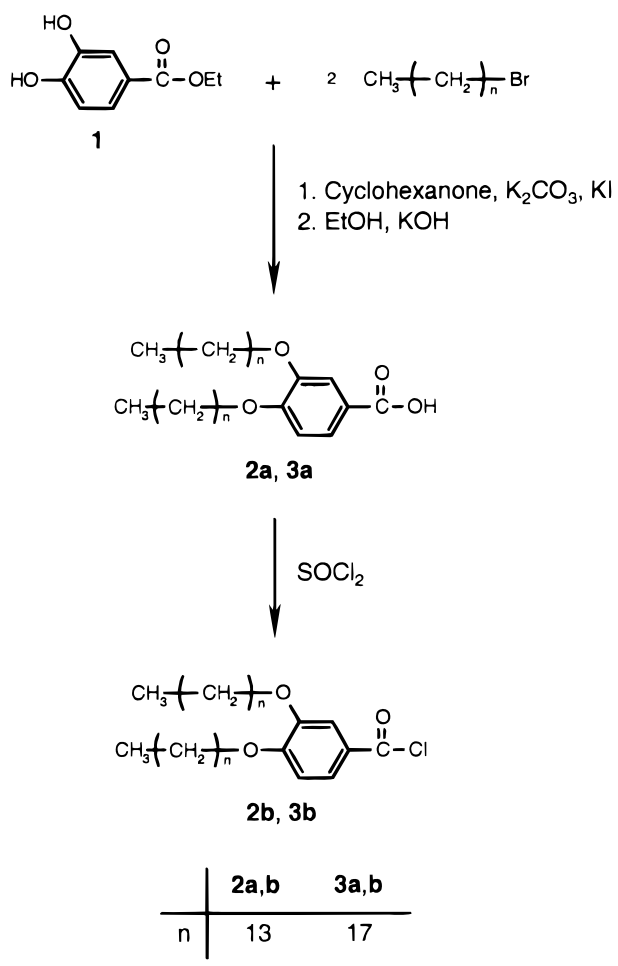

Figure 3. Synthesis of 3,4-(alkyloxy)benzoic acid chlorides $\mathbf{2 b}$ and $\mathbf{3 b}$.

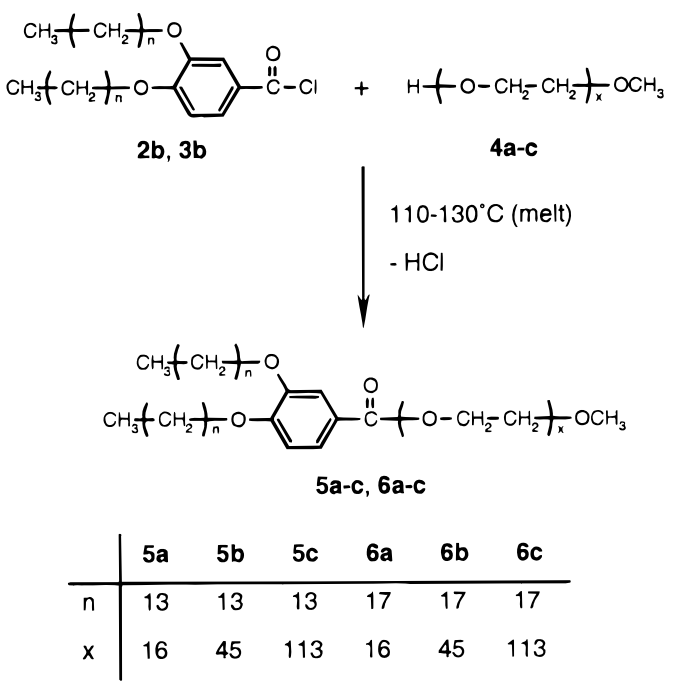

Figure 4. Synthesis of amphiphilic AB-diblock copolymers $5 \mathbf{a}-\mathbf{c}$ and $6 \mathbf{a}-\mathbf{c}$.

Synthesis of AB-Diblock and ABA-Triblock Copolymers. Three series of nonionic surfactants were synthesized, two of them based on poly(ethylene glycol) mono methyl ether (AB-diblock copolymers $\mathbf{5 a}-\mathbf{c}, \mathbf{6 a - c}$ ) and one based on $\alpha, \omega-$ dihydroxy-poly(ethylene glycol) (ABA-tribl ock copolymers 8ae). The poly(ethylene glycol) unit was coval ently attached to the hydrophobic moiety by a coupling procedure depicted in Figures 4 and 5 . As a representative example, the synthesis of triblock copolymer $\mathbf{8 c}$ is described in the following. The syntheses of the other block copolymers are carried out in anal ogy to this procedure.

ABA-Triblock Copolymer (8c). $6.0 \mathrm{~g} \mathrm{(3} \mathrm{mmol)} \mathrm{of} \mathrm{poly-}$ (ethylene glycol) (7c) $\left(M_{n}=2000\right)$ and $3.39 \mathrm{~g}(6 \mathrm{mmol})$ of 3,4bis(tetradecyloxy) benzoyl chloride (2b) were placed in a Schlenk tube and heated to $120^{\circ} \mathrm{C}$. Instantaneous development of bubbles in the viscous melt indicated the start of the coupling reaction. The melt was stirred for $26 \mathrm{~h}$, and a continuous vacuum was applied to remove gaseous hydrochloric acid. The reaction mixture was cool ed to room temperature, 


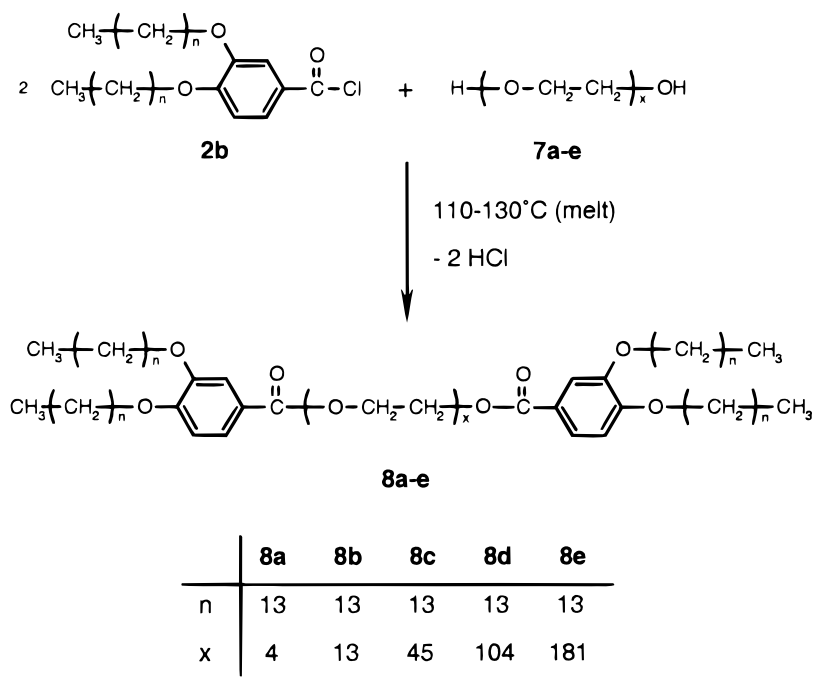

Figure 5. Synthesis of amphiphilic ABA-triblock copolymers $8 \mathbf{a}-\mathbf{e}$.

Table 1. Characteristic Data of AB-Diblock Copolymers $5 a-c$ and $6 a-c$

\begin{tabular}{|c|c|c|c|c|}
\hline polymer & $M_{n, \text { calc }^{a}}{ }^{a}$ & $M_{n, G P C}{ }^{b}$ & $M_{w} / M_{n}{ }^{c}$ & thermal behaviord \\
\hline $5 a$ & 1300 & 1840 & 1.02 & K 40 (156) I \\
\hline $5 b$ & 2550 & 3860 & 1.04 & $\begin{array}{l}\mathbf{K}_{\mathbf{1}} 37(38) \mathbf{K}_{\mathbf{2}} 51 \\
\mathbf{K}_{\mathbf{3}} 54(308)^{*} \mathbf{I}\end{array}$ \\
\hline $5 c$ & 5550 & 8850 & 1.07 & K $60(814)$ | \\
\hline $6 a$ & 1410 & 1940 & 1.08 & $\begin{array}{c}\mathbf{K}_{\mathbf{1}} 13(17) \mathbf{K}_{\mathbf{2}} 32(41) \\
\mathbf{K}_{\mathbf{3}} \mathbf{5 6} \mathbf{K}_{\mathbf{4}} 60(72)^{*} \mathbf{I}\end{array}$ \\
\hline $6 b$ & 2660 & 3500 & 1.06 & K 51 (372) I \\
\hline $6 c$ & 5660 & 7290 & 1.08 & K 58 (866) I \\
\hline
\end{tabular}

a Calculated number-average molecular weight. b Number-average molecular weight determined by GPC (polystyrene standards, eluent: THF). ' Polydispersity index determined by GPC (polystyrene standards, eluent: THF). ${ }^{d}$ Transition temperatures are given in ${ }^{\circ} \mathrm{C}$, enthalpy values (in brackets) are given in $\mathrm{kJ} / \mathrm{mol}$; asterisk denotes the sum of enthalpies for $\mathbf{K}_{\mathbf{2}}+\mathbf{K}_{\mathbf{3}}$ and $\mathbf{K}_{\mathbf{3}}+\mathbf{K}_{\mathbf{4}}$, respectively (DSC, second heating, $10 \mathrm{~K} / \mathrm{min}$ ).

Table 2. Characteristic Data of ABA-Triblock Copolymers 8a-e

\begin{tabular}{|c|c|c|c|c|}
\hline polymer & $M_{n, \text { calc }^{a}}$ & $M_{n, G P C}{ }^{b}$ & $\mathrm{M}_{\mathrm{w}} / \mathrm{M}_{\mathrm{n}}^{\mathrm{c}}$ & thermal behaviord \\
\hline 8a & 1290 & 1890 & 1.02 & K 47 (119) I \\
\hline & 590 & 23 & 1.06 & $\mathbf{K}$ \\
\hline $8 c$ & 3090 & 4710 & 1.02 & K 46 (262) I \\
\hline 8d & 5690 & 8510 & 1.05 & $\mathbf{K}_{\mathbf{1}} 31(61) \mathbf{K}_{\mathbf{2}} 53(631) \mathbf{I}$ \\
\hline $8 \mathbf{e}$ & 9090 & 13230 & 1.09 & K $57(1160) \mathbf{I}$ \\
\hline
\end{tabular}

a Calculated number-average molecular weight. ${ }^{b}$ Number-average molecular weight determined by GPC (polystyrene standards, eluent: THF). ' Polydispersity index determined by GPC (polystyrene standards, eluent: THF). ${ }^{d}$ Transition temperatures are given in ${ }^{\circ} \mathrm{C}$, enthalpy values (in brackets) are given in $\mathrm{kJ} / \mathrm{mol}$ (DSC, second heating, $10 \mathrm{~K} / \mathrm{min}$ ).

dissolved in $30 \mathrm{~mL}$ of THF, filtered and poured into $500 \mathrm{~mL}$ of hexane. The polymer was collected, dissolved in $25 \mathrm{~mL}$ of THF and finally precipitated into $300 \mathrm{~mL}$ of hexane. The compound was dried at $30{ }^{\circ} \mathrm{C}$ in a vacuum (yield: $95 \%$ ). ${ }^{1} \mathrm{H}$ NMR: $\delta 7.65$ (dd, 2H), $7.54(\mathrm{~d}, 2 \mathrm{H}), 6.85$ (d, 2H), $4.43(\mathrm{t}, 4 \mathrm{H})$, $4.04(\mathrm{t}, 8 \mathrm{H}), 3.80(\mathrm{t}, 4 \mathrm{H}), 3.65(\mathrm{~m}, 172 \mathrm{H}), 1.83(\mathrm{~m}, 8 \mathrm{H}), 1.15-$ $1.45(\mathrm{~m}, 88 \mathrm{H}), 0.88(\mathrm{t}, 12 \mathrm{H})$.

The ${ }^{1} \mathrm{H}$ NMR shifts of ABA-triblock copolymers $\mathbf{8 a}, \mathbf{b}$ and $\mathbf{8 d}, \mathbf{e}$ are identical to the shifts reported above. The integral value of the signal at $3.65 \mathrm{ppm}$ varies due to the different composition of the block copolymers. The ${ }^{1} \mathrm{H}$ NMR shifts of AB-diblock copolymers $\mathbf{5 a}-\mathbf{c}$ and $\mathbf{6 a}-\mathbf{c}$ are also identical to the shifts reported above, except an additional peak at 3.35 $\mathrm{ppm}(\mathrm{s}, 3 \mathrm{H})$ which indicates the methoxy endgroup of the PEG segment. Tables 1 and 2 summarize the molecular weight data and the phase transitions of the $A B$-diblock copolymers $\mathbf{5 a}-\mathbf{c}, \mathbf{6 a}-\mathbf{c}$ and of the ABA-triblock copolymers $\mathbf{8 a}-\mathbf{e}$. The polydispersity indices of the AB-diblock copolymers (1.02-1.08) and of the ABA-triblock copolymers (1.02-1.09) are as low as the indices of the pure poly(ethylene glycol) mono methyl ethers (1.07-1.11) and of the pure poly(ethylene glycol)s (1.04-1.12), respectively. This indicates a complete coupling reaction.

Sample Preparation. All samples were prepared as described previously. ${ }^{9}$ A molar ratio of pentanol to surfactant molecules (DMPC + PEG-surfactant) of $4.0 \pm 0.5$ was maintained for all samples in order to ensure that the surfactant chains would always be in the melted state.

Investigation of Physical Properties. The gel behavior of each sample was determined by the inversion test defined previously. ${ }^{9}$ Samples were examined on a macroscopic scale in natural and polarized light and also on a microscopic scale using optical microscopy and X-ray scattering as described previously. ${ }^{9}$

\section{Results and Discussion}

Synthesis. A series of novel ABA-triblock copolymers $(\mathbf{8} \mathbf{a}-\mathbf{e})$ was synthesized by coupling of 3,4-bis(tetradecyloxy) benzoic acid chloride (2b) with $\alpha, \omega$ dihydroxy-poly(ethylene glycol) (Figure 5). The molecular weight of the PEG segment ranged between 200 and 8000 . The condensation reaction was carried out in the melt and driven to completion by evaporation of the hydrochloric acid in a vacuum. In addition, two series of AB-diblock copolymers $(\mathbf{5 a}-\mathbf{c}, \mathbf{6 a}-\mathbf{c})$ were synthe sized in a similar way by coupling of poly(ethylene glycol) mono methyl ether with 3,4-bis(tetradecyloxy) benzoic acid chloride (2b) and 3,4-bis(octadecyloxy) benzoic acid chloride (3b), respectively (Figure 4). The molecular weight of the PEG segment was varied in the range of $M_{n}=750-5000$. The molecular weight data as well as the phase transitions for both block copolymer series are summarized in Tables 1 and 2 .

Gelling Properties. In this section, we describe the gelation properties of the ABA-triblock copolymers synthesized here. We compare the gels obtained in systems containing the novel triblock copolymers with gels produced in systems containing the diblock copolymers and note the similarities and differences.

We have found, at certain concentrations, that the ABA-triblock copolymers $\mathbf{8 c}, \mathbf{8 d}$, and $\mathbf{8 e}$ can induce gelation of the fluid $\mathrm{L}_{\alpha}$ phase in a manner analogous to the AB-diblock copolymers of the series $\mathbf{5 a}-\mathbf{c}$ and $\mathbf{6 a}-$ c. The phase diagram for the amphiphilic ABA-triblock copolymer 8 e showing the $L_{\alpha}$ and $L_{\alpha, q}$ regions is shown in Figure 6 with the water weight fraction $\Phi_{w}$ plotted vs the mol \% of amphiphilic ABA-triblock copolymer $\mathbf{8 e}$ $\left(C_{P E G}\right)$ in the total lipid content of the membrane. The phase behavior of these ABA-triblock copolymers is qualitatively much like the AB-diblock copolymers. ${ }^{8,9}$ Gels are obtained with very small amounts of CPEG (CPEG $\sim 2$ ) and the amount of amphiphilic ABA-triblock copolymer required for gelation decreases as the amount of water is increased. However, quantitatively, the phase behavior of the ABA-triblock copolymers is different than the diblock copolymers. The one phase region for systems containing the ABA-triblock copolymer is much narrower as a function of water weight fraction and the upper two-phase boundary occurs as a much lower $\Phi_{\mathrm{w}}$. This second point will be discussed more fully later.

Figure 7 shows four different test tubes which have just been tilted in the horizontal position in order to illustrate the similarities in flow properties between the gels obtained by addition of either the ABA-triblock or the AB-diblock copolymer. Sample A and B contain 4 


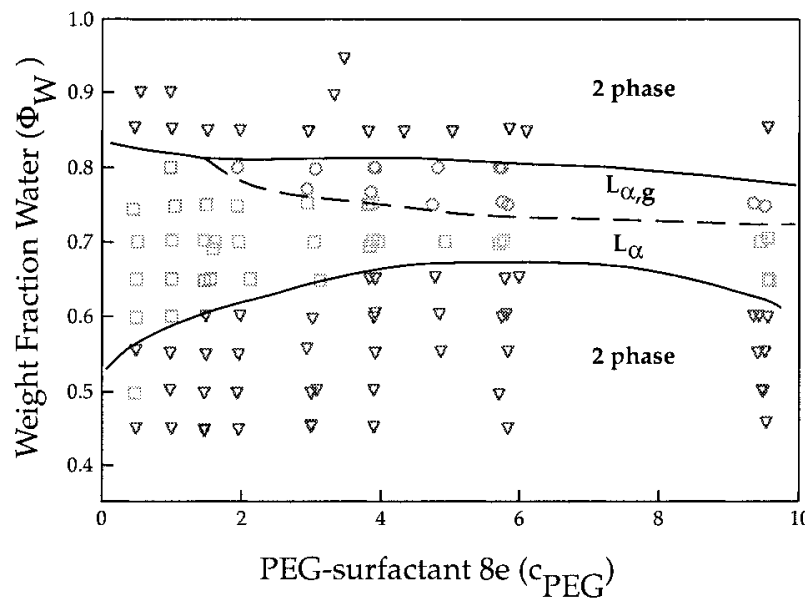

Figure 6. Phase diagram of the quaternary system composed of water, pentanol, DMPC, and the amphiphilic ABA-triblock copolymer $\mathbf{8 e}$. The water weight fraction $\Phi_{\mathrm{w}}$ is plotted vs the concentration of the block copolymer $\mathrm{C}_{\mathrm{PEG}}\left[\mathrm{C}_{\mathrm{PEG}}=(\mathrm{mol} \mathbf{8 e} /(\mathrm{mol}\right.$ $8 \mathbf{e}+$ mol DMPC))100]. The transition between the $L_{\alpha}$ and $L_{\alpha, g}$ phases is denoted by a dashed line and the single phase to two phase transitions are shown as solid lines.

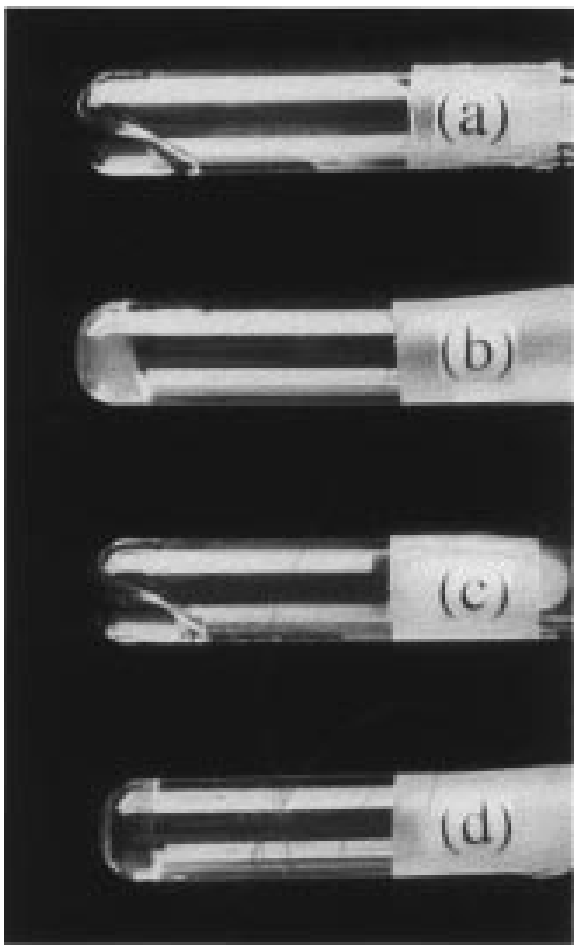

Figure 7. Series of test tubes filled with different mixtures of copolymer, water, cosurfactant, and DMPC tilted horizontally to demonstrate the gelation properties of these novel copolymers: (a) a fluid $L_{\alpha}$ phase containing the amphiphilic AB-diblock copolymer $\mathbf{6 b}$ of composition $\Phi_{\mathrm{w}}=74 \mathrm{wt} \%$, CPEG $=$ 4.0\%; (b) a gel $L_{\alpha, g}$ phase containing the amphiphilic $A B$ diblock copolymer $\mathbf{6 b}$ of composition $\Phi_{\mathrm{w}}=80 \mathrm{wt} \%$ and $\mathrm{CPEG}_{\mathrm{PE}}=$ $4.0 \%$; (c) a fluid $L_{\alpha}$ phase containing the amphiphilic $A B A-$ triblock copolymer 8 e of composition $\Phi_{w}=70$ wt $\%$ and CPEG $=4.9 \%$; (d) a gel $L_{\alpha, g}$ phase containing the amphiphilic $A B A-$ triblock copolymer 8 e of composition $\Phi_{\mathrm{w}}=75 \mathrm{wt} \%$ and $\mathrm{CPEG}_{\mathrm{PEG}}$ $=4.9 \%$.

mol \% of amphiphilic AB-diblock copolymer $\mathbf{6 b}$ with 74 and 80 wt \% water, respectively. Sample C and D contain 4.9 mol \% of amphiphilic ABA-triblock copolymer 8 e at 70 and 75 wt \% water, respectively. It is obvious that the flow characteristics of the gels produced with either diblock or triblock copolymers are comparable. For systems containing either the diblock or
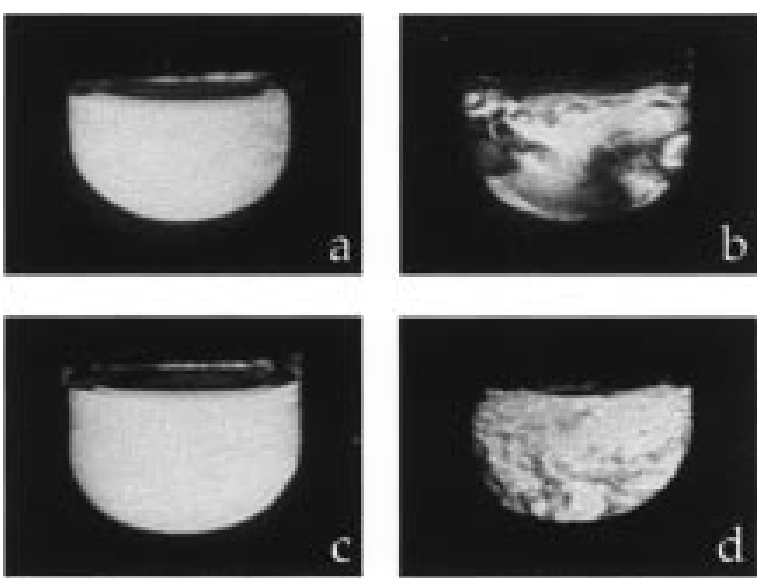

Figure 8. Same test tubes as in Figure 7 viewed between crossed polarizers showing that these samples are bir efringent, demonstrating the liquid crystalline nature of the $L_{\alpha}$ and $L_{\alpha, 9}$ phases: (a) a fluid $L_{\alpha}$ phase containing the amphiphilic $A B$ diblock copolymer $\mathbf{6 b}$ of composition $\Phi_{\mathrm{w}}=74 \mathrm{wt} \%$ and $\mathrm{CPEG}_{\mathrm{A}}=$ 4.0\%; (b) a gel $L_{\alpha, g}$ phase containing the amphiphilic $A B-$ diblock copolymer $\mathbf{6 b}$ of composition $\Phi_{\mathrm{w}}=80 \mathrm{wt} \%$ and $\mathrm{CPEG}_{\mathrm{PE}}=$ $4.0 \%$; (c) a fluid $\mathrm{L}_{\alpha}$ phase containing the amphiphilic ABAtriblock copolymer 8e of composition $\Phi_{\mathrm{w}}=70 \mathrm{wt} \%$ and $\mathrm{C}_{\mathrm{PEG}}$ $=4.9 \%$; (d) a gel $\mathrm{L}_{\alpha, g}$ phase containing the amphiphilic ABAtriblock copolymer 8 e of composition $\Phi_{\mathrm{w}}=75 \mathrm{wt} \%$ and $\mathrm{CPEG}_{\mathrm{PE}}$ $=4.9 \%$.

triblock copolymers synthesized here, the $L_{\alpha, g}$ phase occurs in water swollen lamellar $L_{\alpha}$ phases. Although the flow properties of the gels containing the diblock and triblock copolymers are similar, the stability of the gels differs. Gels formed by addition of diblock copolymers to the $L_{\alpha}$ phase have remained stable up to 2 years. However, the gels formed by addition of the triblock copolymers are metastable and slowly demix on a time scale ranging from several months to a year.

Examination of the same test tubes in polarized light (Figure 8) demonstrates that on a macroscopic scale the $\mathrm{L}_{\alpha}$ and $\mathrm{L}_{\alpha, \mathrm{g}}$ phases containing either the diblock or triblock copolymers are liquid-crystalline in nature. The $L_{\alpha}$ phase does not show any texture at this length scale. In contrast, the $L_{\alpha, g}$ phase generally displays a nematiclike texture with a variable density of line defects on a millimeter length scale.

These observations were complemented by the observation of textures by polarized light microscopy. We found that the textures inherent in systems containing the novel ABA-triblock copolymers are analogous to those seen in the AB-diblock copolymer systems. ${ }^{9}$ A defining signature ${ }^{8,9}$ of the biogel $L_{\alpha, g}$ regime as it sets in from the fluid lamellar $L_{\alpha}$ phase is the proliferation of layer-dislocation type defects which are stabilized by the segregation of the block copolymers to the high membrane curvature defect regions connecting the membranes. This is illustrated in Figure 9 which shows the optical texture of a fluid $L_{\alpha}$ phase containing a very small amount of an amphiphilic ABA-triblock copolymer and $a L_{\alpha, g}$ biogel containing a larger amount of the same triblock copolymer. The textures of the fluid $L_{\alpha}$ phase show the usual black homeotropic regions broken by oily streaks which are the typical defects of Iyotropic $L_{\alpha}$ phases. ${ }^{15}$ In contrast, the gel texture shows a proliferation of very thin line defects which we call "whisps". The gel phase is then characterized by a highly defected microstructure comprised of a network of connected membrane bilayers with the block copolymers segregated to the high curvature regions. This leads to 

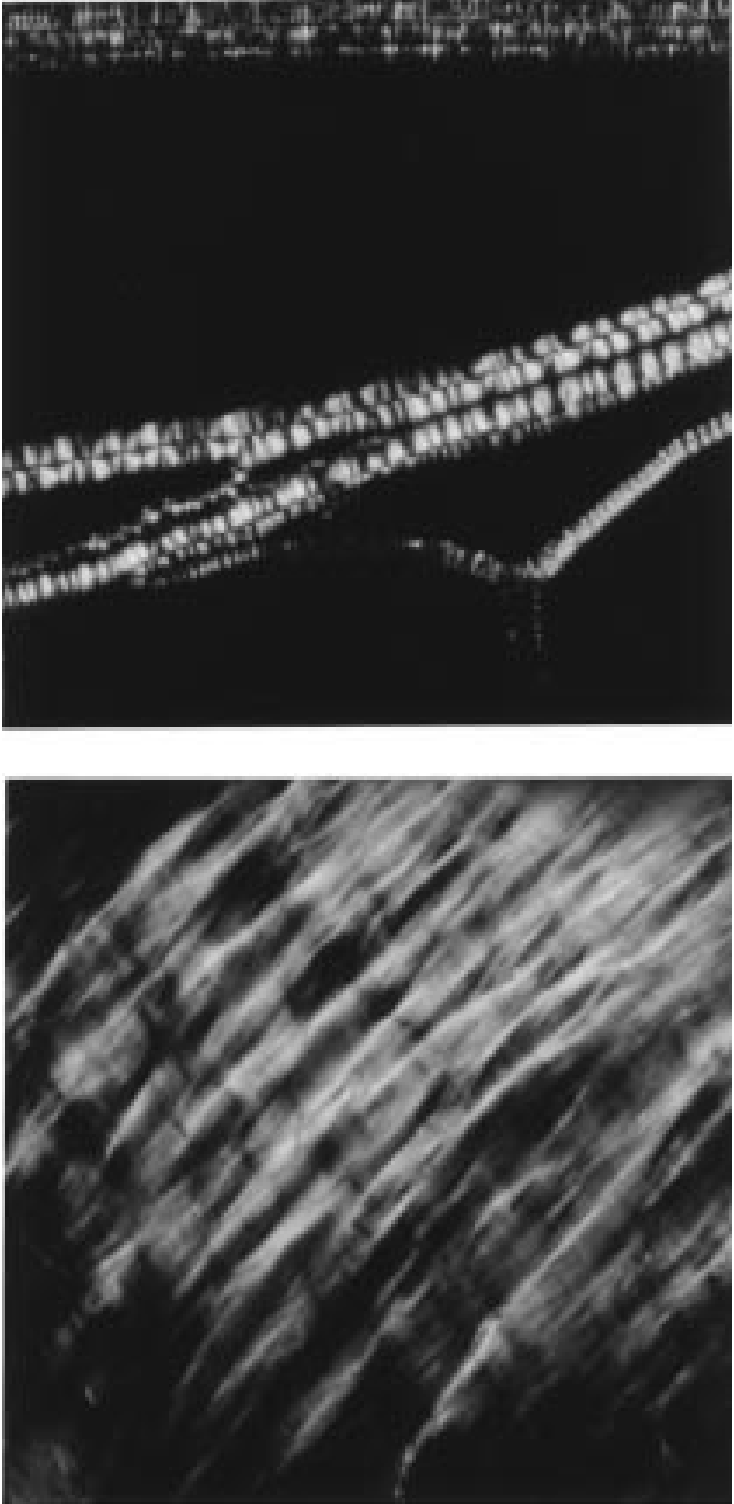

Figure 9. Polarized light microscopy of samples in the $\mathrm{L}_{\alpha}$ and $L_{\alpha, g}$ regime showing distinct textures. The fluid $L_{\alpha}$ phase (shown at top) shows oily streak defects while samples in the $L_{\alpha, g}$ phase (shown at bottom) reveal a proliferation of very thin line defects. The fluid $L_{\alpha}$ sample contains the amphiphilic ABA-triblock copolymer 8 e of composition $\Phi_{w}=75$ wt $\%$ and $C_{P E G}=0.5 \%$. The gel $L_{\alpha, g}$ sample contains the amphiphilic ABAtriblock copolymer 8 e of composition $\Phi_{\mathrm{w}}=75 \mathrm{wt} \%$ and $\mathrm{CPEG}_{\mathrm{PEG}}$ $=4.9 \%$.

random layer orientation domains on a semi macroscopic length scale which may induce elasticity and thus gellike behavior because domains which have their layer normals with a finite projection along the flow direction will resist shear to avoid tilting of layers. ${ }^{16}$ The same pattern of proliferation of layer-disl ocation type defects was seen in samples containing the AB-diblock copolymers synthesized here. ${ }^{9}$

Figure 10 shows small-angle X-ray scattering scans of unoriented samples composed of the amphiphilic ABA-triblock copolymer $\mathbf{8 e}, \mathrm{DMPC}$, pentanol, and water in the fluid and gel phases. The 00l peaks of the lamellar structure are clearly observed for both phases, demonstrating that there is no structural phase transition at this length scale between the fluid and gel phases as was the case for the AB-diblock copolymers. The fluid $L_{\alpha}$ phase sample examined by $X$-ray scattering

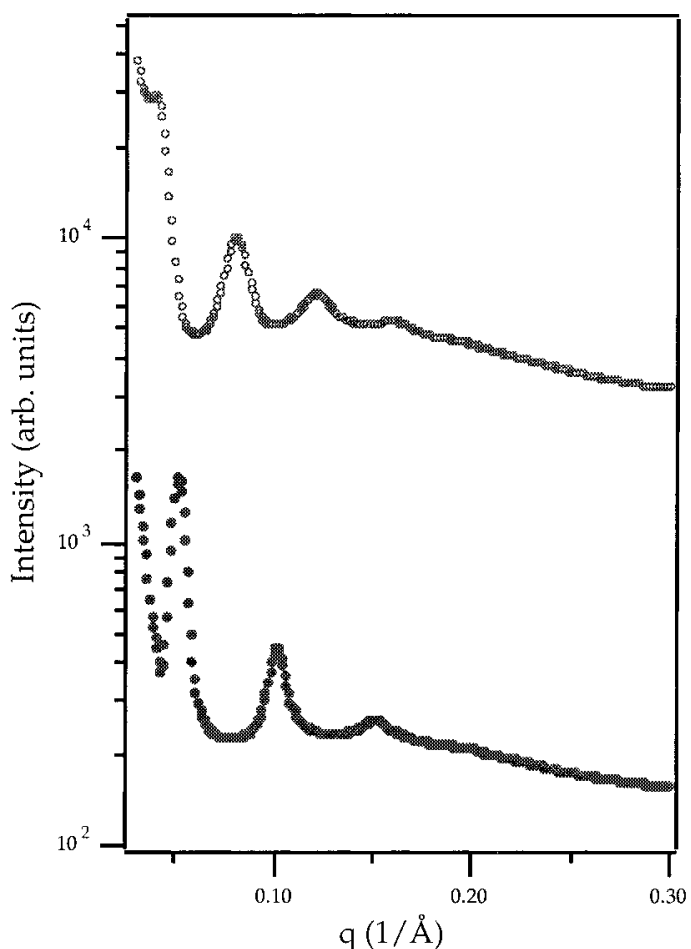

Figure 10. Small-angle X-ray scattering scans of unoriented samples in the fluid and gel phases. Open symbols denote the gel $\mathrm{L}_{\alpha, g}$ phase containing the amphiphilic ABA-triblock copolymer $8 \mathbf{e}$ of composition $\Phi_{w}=70$ wt $\%$ and $C_{P E G}=4.85 \%$. Closed symbols show the fluid $L_{\alpha}$ phase containing the amphiphilic ABA-triblock copolymer $\mathbf{8 e}$ of composition $\Phi_{w}=75 \mathrm{wt} \%$ and $\mathrm{CPEG}=4.85 \%$. The interlamellar spacing for the gel sample is $155 \AA$ and for the fluid sample is $122 \AA\left(d=2 \pi / q_{1}\right)$.

(Figure 10, closed symbols) occurs just above the lower two-phase boundary (Figure 6) and shows an interlamellar spacing of $122 \AA$. I nterestingly, this spacing just allows for the incorporation of the PEG-moiety of the ABA-triblock between the membranes. We can cal culate the water spacing between the membranes by first obtaining the membrane thickness from $d=\delta / \phi_{\mathrm{m}},{ }^{9}$ where $\mathrm{d}=$ interlamellar spacing, $\delta=$ membrane thickness, and $\phi_{\mathrm{m}}=$ the volume fraction of membrane in the system. For this system, $\delta=29 \AA$. Therefore, the water spacing for the fluid $L_{\alpha}$ sample is $d_{w}=d-\delta=93 \AA$. The radius of gyration for the PEG chain of amphiphilic ABA-triblock copol ymer 8 e is calculated from $R_{g}=a N^{3 / 5}$ ( $\mathrm{a}=$ effective monomer length $=3.6 \AA ;{ }^{9} \mathrm{~N}=$ number of monomers $=181$ for PEG $M_{n}$ of 8000 ) which gives $R_{g}=$ $81.5 \AA$. For the PEG segment to insert between the membranes, it is necessary for $d_{w}$ to be larger than the natural extension of the polymer moiety, $R_{g}$. We see that the lower two-phase boundary just fulfills this requirement. This suggests that the system is stable in a lamellar regime only when the PEG segment can be incorporated between the membranes. The ABdiblock copolymers show the same behavior with the lower two-phase boundary occurring at a water spacing just larger than the $\mathrm{R}_{\mathrm{g}}$ of the polymer moiety. ${ }^{8,9}$

In contrast, the upper two-phase boundary of the system containing the novel ABA-triblock copolymer occurs at a water spacing much smaller than that seen in the AB-diblock copolymer systems. The ABA-triblock gel $L_{\alpha, g}$ sample demonstrates an interlamellar spacing of $155 \AA$ corresponding to a water spacing of $126 \AA$ (Figure 10, open symbols). I ncorporation of any more water results in phase separation. Therefore, the upper 
two-phase boundary in this system occurs at water spacings only slightly larger than $126 \AA$. This behavior is dramatically different than that seen in systems incorporating the AB-diblock copolymers. In these systems, the lamellar regions remain one phase up to dilutions which correspond to an interlamellar spacing of about $360 \AA$ and a water spacing of $334 \AA$. This separation is much larger than the radius of gyration $R_{g}$ of the PEG chain $\left(R_{g}=62 \AA\right.$ for a PEG $M_{n}$ of 5000), which suggests a mushroom type conformation for the AB-diblock copolymer (Figure la). The behavior seen in the ABA-triblock system is evidence of the crossbridging configuration (Figure $1 \mathrm{~b}$ ) for the ABA-triblock copolymer where the multilayer membrane cannot support separations much larger than a significantly stretched PEG segment. It also suggests that the looping configuration is not significantly lower in energy cost than the bridging configuration. In this case, the lamellar hydrogel appears to be based on 2-dimensional fluid membranes, but where the membranes have transient cross-links through the 1-dimensional polymers.

\section{Conclusions}

We have presented a straightforward method to synthesize ABA-triblock copolymers consisting of hydrophobic A-blocks and a hydrophilic B-block which act as gelling agents for the lamellar liquid crystalline $L_{\alpha}$ phase. The anchoring strength of these block copolymers can be easily varied by increasing the number of hydrocarbons in the alkyl chains and/or by varying the number of alkyl chains attached to the benzene ring (13). The hydrophilic character of these block copolymers depends on the chain length of the poly(ethylene glycol) segment. For future work this will give us a large variety of control parameters for further investigations on the structure-property relationships of these block copolymers. We have shown that the ABA-triblock copolymers presented here can induce gelation of fluid $\mathrm{L}_{\alpha}$ phases in a way similar to that previously reported for the AB-diblock copolymers. However, we have also found that the intermembrane spacing of samples containing the $\mathrm{AB}$-diblock copolymer dilutes to a much greater extent than that of samples containing ABAtriblock copolymers. This strongly suggests that the ABA-triblock copolymers adopt the cross-bridging con- figuration and that the looping configuration is not a significantly lower energy configuration.

Acknowledgment. The authors gratefully acknowledge Y. Heischkel (University of Bayreuth) for her help with the GPC measurements. U.S. acknowledges the support of the Deutsche F orschungsgemeinschaft (DFG) for a postdoctoral fellowship (Schu 1247/1-1). This research is supported by NSF Grant No. DMR-9624091, the donors of the Petroleum Research Fund, administered by the American Chemical Society, Grant No. 31352-AC7, and Los Alamos Grant STB/U C:96-108.

\section{References and Notes}

(1) See, e.g.: DeRossi, D.; Kajiwara, K.; Osada, Y.; Yamauchi, A. Polymer Gels: Fundamentals and Biomedical Applications; Plenum Press: New York, 1991.

(2) Peppas, N. A.; Langer, R. Science 1994, 263, 1715.

(3) (a) Allen, T. M.; Chonn, A. FEBS Lett. 1987, 223, 42. (b) Gabizon, A.; Papahadjopoulos, D. Proc. Natl. Acad. Sci. U.S.A. 1988, 85, 6949.

(4) Lasic, D. D. Liposomes: From Physics to Applications; Elsevier: Amsterdam, 1993.

(5) (a) See, e.g.: Perspective on "Liposomes Revisited". Lasic, D. D.; Papahadjopoulos, D. Science 1995, 267, 1275. (b) Lasic, D. D.; Martin, F. J., Eds.; Stealth Liposomes; CRC: Boca Raton, FL, 1995.

(6) Lee, V. H. L., Ed.; Peptide and Protein Drug Delivery; M. Dekker, Inc.: New York, 1991.

(7) Bailey, F. E., J r.; Koleske, J . V. Poly(ethyleneoxide); Academic Press: New York, 1976.

(8) Warriner, H. E.; Idziak, S. H. J .; Slack, N. L.; Davidson, P.; Safinya, C. R. Science 1996, 271, 969.

(9) Warriner, H. E.; Davidson, P.; Slack, N. L.; Schellhorn, M." Eiselt, P.; I dziak, S. H. J .; Schmidt, H.-W.; Safinya, C. R. J . Chem. Phys. 1997, 107, 1 .

(10) Safinya, C. R.; Sirota, E. B.; Roux, D.; Smith, G. S. Phys. Rev. Lett. 1989, 62, 1134.

(11) Safinya, C. R.; Roux, D.; Smith, G. S.; Sinha, S. K.; Dimon, P.; Clark, N. A.; Bellocq, A. M. Phys. Rev. Lett. 1986, 57, 2718.

(12) Malthête, J .; Levelut, A. M.; N guyen, H. T.J . Phys. Lett. Paris 1985, 46, L875.

(13) Lattermann, G.; Staufer, G. Liq. Cryst. 1989, 4, 347

(14) Staufer, G.; Lattermann, G. Macromol. Chem. Phys. 1991 192, 2421.

(15) (a) Asher, S. A.; Pershan, P. S. Biophys. J . 1979, 27, 393. (b) Schneider, M. B.; Webb, W. W., J . Phys. Fr. 1984, 45, 273. (c) Boltenhagen, P.; Lavrentovich, O. D.; Kleman, M. Phys. Rev. A 1992, 46, R1743. (d) Boltenhagen, P.; Kleman, M.; Lavrentovich, O. C. R. Acad. Sci. Paris II 1992, 315, 931. (e) Boltenhagen, P.; Kleman, M.; Lavrentovich, O. J . Phys. II Fr. 1994, 4, 1439.

(16) Kawasali, K.; Onuki, A. Phys. Rev. A 1990, 42, 3664.

MA980901G 